\title{
How Children Acquire Language-specific Ways of Partitioning Space: Creating a Semantic Category System Using Semantic Primitives
}

\author{
Youjeong Park \\ Cornell University, USA
}

\author{
Jinwook Kim* \\ Myongji Univeristy, South Korea
}

\begin{abstract}
This paper reviews Grammatical Mapping theory, a recently proposed theoretical paradigm for understanding children's acquisition of syntax, and ventures to apply the theory to the acquisition of semantics. Particularly, we focused on the domain of space, and proposed how children might acquire a unique system of spatial words in their mother tongue. Based on our review of evidence, we propose that there may be universal semantic primitives that serve as foundations of word meanings. We also propose that children must learn their mother tongue's semantic category system of spatial relations, from real time data. Finally, we argue that children's learning of word meanings may involve creation of a theory that makes sense to the child, and that this process of theory creation is possibly guided by universal principles and parameters.
\end{abstract}

Keywords: Grammatical Mapping theory, spatial language, semantics, universal principles

Grammatical Mapping theory is a theoretical paradigm that has recently been proposed in the syntactic acquisition. One distinctive characteristic of this theoretical paradigm is that it attempts to account for the role of experience over time, while acknowledging the existence and importance of universal principles (Lust, 2012). In the present paper, we venture to apply the Grammatical Mapping (GM) theory to the acquisition of semantics, particularly children's acquisition of spatial word meaning. We first briefly summarize the GM theory, and review and critique critical existing theories of word meaning acquisition. Next we examine evidence for 'semantic primitives' and cross-linguistic variation in spatial semantic categorization. Then we review what is known about the

* Corresponding Author: Jinwook Kim, Assistant Professor, Department of Child Development and Education, Myongji University, 34 Geobukgol-ro, Seodaemun-gu, Seoul, 120-728, Korea. E-mail: jwkddorang2@mju.ac.kr development in language-specific word meaning acquisition. Based on that review, we finally propose a basic framework for a theory of word learning development.

\section{Theoretical Background}

\section{The Grammatical Mapping (GM) Theory}

The GM theory is a theory of syntactic acquisition. According to the GM theory, children have Universal Grammar (UG) that consists of principles and parameters that are necessary to the "creating" of a language. The UG is considered to be continuously available to the child. Also, the GM theory posits that children's real-time experience is Specific Language Grammar (SLG) data and that children must acquire their SLG system. The acquisition of SLG involves the process of 
creating a theory of SLG. In constructing a theory of SLG, the child is engaged in grammatical mapping in which the child is mapping from one form of grammar (i.e., UG) to another (i.e., SLG). In other words, the child builds explanations of the ambient language's grammar (SLG) using UG as a guideline.

This theory implies that children's syntax acquisition is neither solely constrained by biological programming nor an automatic product of experience and regularities. Rather, it is seen as an integration of experience and biological programming. Also, the GM theory claims that the child's theory about SLG changes over time. Thus, the true development lies in SLG.

This theory may provide a useful framework for understanding the acquisition of word meaning, especially, spatial words. Experience with space is almost universal to all humans. Thus, it is not unlikely that humans have biologically programmed principles for representing space and spatial relations. However, it is known that languages have different systems to lexicalize the spatial relations, which means that children must learn different ways of packaging spatial relations into words. Based on this reasoning, one question arises: How do children acquire more or less unique spatial words in their language, based on the universal cognition? This paper explores the question.

To briefly sketch our proposal first, we propose that children have universal principles and parameters that are essential to creating a spatial language. We also propose that these universal principles and parameters (UP) enable children's rudimentary spatial categorization during their preverbal period, and later guide children's creation of a theory of language specific semantic system. More specifically, we propose that children acquire spatial word meanings through mapping the spatial words to those rudimentary categorical distinctions or adjusted categorical distinctions. The adjusted categorical distinctions are achieved through combining and dividing the primitive spatial categorization, with the guidance of UP.

\section{Existing Theories of Word Meaning Development}

Several researchers have proposed theories of word meaning acquisition. Many of the theories appear to have been advanced to explain how children can pick up the referents of words (mostly nouns) so quickly. These theories include constraints theory (e.g., Markman, 1989), social pragmatic theory (e.g., Tomasello, 2000), and emergentist coalition model (Hirsh-Pasek, Golinkoff, \& Hollich, 2000) (see Appendix for a summary of these theories). Although these theories can explain how the scope of possible meanings can be narrowed down so that word learning can occur efficiently, they do not explain the other kind of word learning: the acquisition of word meanings that takes place over a relatively long time. Particularly, relational words such as verbs and prepositions are known to take long for children to achieve adult-like understanding of meanings (Gentner, 1982; Saji et al., 2011). Also, those theories cannot explain how children learning different languages can acquire relational words of different referential scopes.

Unlike those theories, there are a handful of other theories that have been created to explain the developmental course of word meanings. These theories have focused on how word meanings change from initial, immature meanings to later, mature meanings. In this section, we briefly review these theories of development relevant to word meaning.

Classic Abstraction Theory. By some earlier theorists (e.g., R. Brown, 1958), the acquisition of word meaning was considered to be a function of repeated exposure to particular word-referent pairings, out of which were abstracted sets of defining attributes that determined the referential scope of individual words and the concepts that they mapped. For example, the meaning of ' $d o g$ ' is acquired as a function of repeated exposure to the phonetic sequence $d o g$ coupled with repeated instances of the object, dog, resulting a common set of attributes that is abstracted out of the repeated 
examples of dog. Brown (1958) claimed that children formed hypotheses about the categorical nature of the things named and tested the hypotheses by trying. Adults' correction improves children's hypotheses. Thus, according to this theory, meanings are constructed after linguistic experience, during which children look for properties remaining constant across uses of a word by adult speakers.

Missing-feature Theory. Unlike the classic abstraction theory, another theoretical approach views that children bring pre-established meanings to the task of word meaning acquisition. Under this view, children's prelinguistic concepts first emerge out of cognitive development, and the acquisition of word meaning is the mapping of language forms to the child's nonlinguistic concepts (Clark \& Clark, 1977). Thus, the child's concepts determine the referential scope of a word. This way, children's growing conceptual knowledge plays an important role in word meaning acquisition.

Under this conceptually based view, the missing-feature theory (E. Clark, 1973) posits that the child's word meanings are incomplete and differ from adults' word meanings. While the full meaning of a word contains multiple semantic features, children initially represent only some of the semantic features that tend to be perceptually salient to them (e.g., shape). Thus, children's word meaning acquisition is a process of adding more semantic features to a word meaning until the full meaning is achieved. One consequence of this hypothesis is that the referential scope of a word is initially large and becomes narrower as more semantic features are accumulated as the meaning of a word. Thus, children will show overextension during the course of word learning (e.g., extending the verb "open" to peeling fruit, turning a light or a tap on, and unlacing shoes).

The missing-feature theory also assumes hypothesis testing. To work out the meanings of words, children first form hypotheses about word meanings by drawing upon their conceptual knowledge. Once they tie the supposed meaning of a word to a specific concept, next they use the word with the hypothesized meaning as a rule for how to use it in other occasions. They find out more about how well they themselves are understood when using it and how other people use it. This way, they gradually adjust their rule until it eventually coincides with the adult's (Clark \& Clark, 1977).

Missing-features-plus-haphazard-example Theory. Another conceptually based theory was proposed by Carey (1978), who also viewed that a word meaning could be decomposed into multiple features and that the child developed incomplete representations along the way of acquisition of word meanings. For example, in her study of children's acquisition of spatial adjectives, Carey (1978) found that children early mapped polarity to the spatial adjectives but linked the exact dimension of comparison of the spatial adjectives much later. For example, young children provided "little" as the opposites of "tall," "wide," "high," and "deep." Thus, Carey agreed with Clark in that (1) children map words to their pre-established concepts and that (2) there are missing features in immature word meanings.

However, Carey (1978) pointed out another characteristic of immature word meanings. That is, the immature lexical meanings for relational terms such as spatial adjectives might contain information about some particular objects to which each term applies. For example, the child's word meaning of tall might include that it applies to buildings and people. Thus, the child may acquire the meanings of relational terms by first learning idiosyncratic, object-particular meanings and later learning a more general and abstract concept that applies to a wider class of objects. The earlier meaning may be associated with objects, and later meaning may be isolated from the objects.

Multifactorial Theory. While those conceptually based theories assume the major role of preestablished concepts in word meaning acquisition, Bowerman (1989) viewed that the strength and specificity of the cognitive predispositions for semantic organization was 
overstated by those theories. She emphasized that the child might be sensitive to their ambient language input and acquiring word meanings in the specific language from a very young age. She suggested that children also draw upon perceptual sensitivities and conceptual biases they bring with them to the task (Bowerman \& Choi, 2001), thus in the process of acquiring word meanings, children "do not waste time on crazy possibilities and have some sense of what properties of situations are likely to matter" (Bowerman \& Choi, 2001, p. 503). Further, she proposed that characteristics of the language influence children's construction of semantic categories as well, including the frequency with which given words are used in the input, the consistency of the range of referents for which the words are used, and the degree of overlap in the referents for which different words are used (Bowerman \& Choi, 2001). Thus, Bowerman's multifactorial theory is distinguished from all other theories above in that it considers crosslinguistic differences in word meaning organization and how children learn the specific language semantic categories.

Another important difference between Bowerman's theory and other theories is that in Bowerman's theory, the overextension errors occur relatively later, as the child gains insight that not all qualities need to be shared and undergoes the adjustment process of decomposing and recomposing abstract features in new ways. Before gaining this insight, children's uses of new words are closely tied to the ways adults use the same words. After this restricted-referent period, the child's use of the word would be extended to other referents in the same category (Bowerman, 1989). Words might be deliberately used to label extremely dissimilar exemplars sharing only a few features, across adult grammatical categories. For example, a child generalized the verb "kick" to sudden contact of a limb with any object and to throwing. During this process, children analyze word meanings by way of detailed comparisons of repeated instances in which they hear words, and finally reach the adult-like breadth of meaning. Thus, according to this model, at least in some cases the development of word meaning follows a path from 'too specific' through 'too general' to 'just right general' and that the child's misuses of words reflect their insight and broad definitions of meaning.

Other Theories and Summary. There are also other theories that are relevant to the development of word meaning. Because of the space limit, summaries of those theories are not presented here. To briefly mention, Nelson (1985) suggested that the early word meaning is context-bound and mapped onto unpartitioned, holistic representations of events and that only later words are mapped onto categories. Also, Barrett (1995) proposed that early lexicons have both context-bound words and categorical words, and that they develop following distinct routes to conventional meaning.

In sum, a handful of theories have attempted to explain how word meaning is acquired over an extended time. They have different positions about whether the primitive meanings are in place before or after language experience, whether children expect that words refer to "categories" from the beginning, and how many elements the initial meanings conflate. While all of these theories have important insights and unique contributions, Bowerman's theory appears to be the only one that has considered the fact that children must learn different semantic categorization systems in different language communities. Bowerman's theory has placed more emphasis on the role of specific language input, while acknowledging the role of perceptual sensitiveness. However, the theory does not appear to pay much attention to the cross-linguistic commonalities in essential elements of features to which children demonstrate perceptual sensitiveness.

\section{Evidence for Semantic Primitives in Spatial Domain}

The review of theories highlights the central 
question about the origin of word meanings. Are there preverbal semantic primitives? Are there conceptual distinctions for objects, relations, properties, and events that serve as foundations of word meanings? In the domain of space, are there pre-linguistic rules for organizing and partitioning spatial relations? Substantial crossand within-language research has appeared to reveal 'semantic primitives.' Below we review the evidence.

First, several earlier researchers suggested the existence of innate cognitive biases in the domain of spatial relations, based on the crosslinguistic data that revealed universal patterns of early spatial word acquisition. For instance, initial semantic categories of children acquiring different languages are highly similar. Children learning English, Turkish, Serbo-Croatian, and Italian acquire spatial terms in a consistent order (e.g., terms for in/on being acquired before front/back) (Johnston \& Slobin, 1979). Also, there is universal development of spatial word production in Danish, English, and Japanese children (Sinha, Thorseng, Hayashi, \& Plunkett, 1994). Across cultures, children begin to talk about space at a similar age, around 16 months (Bowerman, 1996). Both adults and children show biases for processing certain spatial relations such as containment and tight-fit (e.g., Choi \& Hattrup, 2012; Norbury, Waxman, \& Song, 2008; Plumert \& Hawkins, 2001). Further, children share interests in same kinds of spatial activities. Containment seems especially salient to children -young children put things into containers when possible (Clark, 1993). Together, these "similarities" or "universality" appear to support the existence of universal ways to cognitively process spatial experience.

Second, cross-linguistic research provides evidence that at least some spatial concepts do not require spatial language. For example, indigenous Amazonian, Munduruku, use a language that is reported to have few words for geometric or spatial concepts (Dehaene, Izard, Pica, \& Spelke, 2006). They also do not use or draw maps. Dehaene and colleagues showed the Munduruku children and adults panels of six figures. Five of the six figures shared a geometric characteristic and the other one lacked it (e.g., parallel lines with different orientation and distance between the paired lines). When asked to select the "weird" stimulus, the Munduruku children and adults reliably chose the geometrically odd figure correctly. Although these participants were post-linguistic, the finding tells us that they have spatial concepts (grouping spatial entities) independent of corresponding language because Munduruku language has few spatial words. The researchers concluded that the human mind comes equipped with the prerequisites for spatial thought.

Third, stronger support for semantic primitives comes from infant research. Mandler (1992) has pointed out that, if language acquisition depends partly on preverbal concepts, they must already be present by 10 months when children begin to acquire their first spoken words and use them for communication. Indeed, research has shown that preverbal infants conceptualize some spatial relations well before language is acquired (e.g., Aguiar \& Baillargeon, 1998; Baillargeon, 1994; McDonough, Choi, \& Mandler, 2003; Needham \& Baillargeon, 1993). For example, Hespos and Spelke (2004) found that 5-month-old infants in English-monolingual environment distinguished between loose-fitting and tight-fitting joint of two objects. In this experiment, infants were habituated to a single pair of objects jointed in either a loose or tight relation and then were tested with one loose-fit and one tight-fit event. All objects in this experiment were cylindrical shapes, but the spare space between the jointed objects varied among the loose-fit events; and the size of the involved objects varied among the tight-fit events. Infants of 5 months recognized the familiarized fit relation despite the changes in the amount of spare space and object size. Moreover, they recognized the familiar fit relations across variations in a mechanical distinction (i.e., habituated to support relation, tested with containment relation). Thus, 5month-olds partition continuous variations in degree of fit into two discrete categories, crosscutting support and containment relations. Furthermore, 5-month-olds generalize tight- and loose-fit relations within covering events and 
from covering to containment events (Hespos \& Piccin, 2009). Also, English-learning 9-montholds can categorize events with diverse objects on the basis of tight versus loose feature within the containment relation (McDonough, Choi, \& Mandler, 2003). Thus, infants in an Englishspeaking community parse a continuum of spatial events at a boundary point that is not marked in English. These findings collectively provide strong support for the statement that infants pre-linguistically categorize the tight- vs. loose-fit relations.

Infants also show categorical distinction based on the relative locations along a horizontal and vertical axes (i.e., up vs. low, above vs. below, left vs. right) and contact vs. separation (Antell \& Caron, 1985; Gava, Valenza, \& Turati, 2009; Quinn, Cummins, Kase, Martin, \& Weissman, 1996). For example, 3-day-old neonates have been shown to be capable of detecting an invariant left-right relation between a bar and a square despite the changes in absolute location (Gava, Valenza, \& Turati, 2009). Also, 3-monthold infants categorically organized above and below relations in their spatial memory (Quinn, 1994). Infants form abstract representations of above and below relations by the age of 6 months, and between relations by 9 months. Thus, well before they begin to acquire their first spoken words, infants categorically represent relative relations among vertically or horizontally arranged objects.

Another line of research has shown that preverbal infants readily have an abstract categorical representation of containment. At 6 months, infants who viewed four examples of containment relations generalize the containment feature to a novel pair of objects (Casasola, Cohen, \& Chiarello, 2003). They recognize containment events consisting of different objects and appearing in different absolute locations as familiar. Furthermore, the containment category does not seem solely based on perceptual cues (i.e., occlusion of features by the container). For example, 2.5month-olds recognize that containment involves an opening and that the object contained moves with the container (Hespos \& Baillargeon, 2001).
Also, Casasola and colleagues (2003) showed 6month-olds containment events filmed from a high angle so that the contained objects were still visible after containment; the infants still formed the containment category. Thus, infants seem to have rudimentary conceptual notion of containment, even without linguistic partitioning.

Infants also develop knowledge of support relations (e.g., Aguiar \& Baillargeon, 1999; Baillargeon, 2004; Baillargeon, Needham, \& DeVos, 1992; Hespos \& Baillargeon, 2001; Needham \& Baillargeon, 1993; Wang, Baillargeon, \& Paterson, 2005). At 3 months infants expect objects to be supported if they are in full contact with a surface, and otherwise to fall. By 5 months they expect an object to be supported if any part of the object rests on the surface. By 6 months they have begun to differentiate between partial but inadequate support and adequate support. Thus, within a few months, infants construct a primitive concept for the horizontal support relations.

While the knowledge of support relations develops during the first 6 months, research nevertheless has had difficulties finding evidence that young infants have the ability to form a categorical representation of support relations as early as containment (Casasola \& Cohen, 2002). When the diverse examples of English on relations were shown to the infants (support events involving various directions), even 18-month-olds failed to form a categorical representation of support relations. With reduced diversity of orientations and objects in the support events, infants of 14 months and 10 months succeeded in forming the support category. With even more similar exemplars, infants of 8 months generalized the horizontal support relation to novel pairs of objects when the objects had some visual features (Park \& Casasola, under review). Thus, the available data provide no evidence that preverbal infants form an abstract categorical representation that encompasses a wide variety of spatial relations described as on in English. However, they do provide evidence that infants form a categorical representation that encompasses $a$ small set of 
horizontal support relations before they acquire spatial terms.

Altogether, these empirical findings suggest that there are semantic primitives or principles for differentiating and grouping spatial relations pre-verbally. Infants do have some rudimentary conceptual understanding of some spatial relations. Infants do distinguish spatial relations categorically before they acquire spatial terms.

There are several points that should be noted, however. First, infants who have been tested in those categorization studies are mostly infants who hear English as their first language. While this lack of cross-linguistic data needs to be solved by future research, it is unlikely that these young infants acquire the categorical distinctions from the English spatial word input. Second, preverbal infants' primitive categorical distinctions may not be robust. Particularly, they seem fragile when there are objects perceptually highly dissimilar. Note that the objects in Hespos' studies were restricted to cylindrical objects in both habituation and test. In addition, the orientations of two objects' being jointed were also limited to be horizontal. When the same spatial feature, tight fit, was tested perceptually highly diverse objects (Casasola \& Cohen, 2002), infants failed to generalize tight fit as a category even at 18 months (Casasola \& Cohen, 2002). These findings suggest that the semantic primitive "tight fit" may be rather fragile and that young children may perceive subtypes of tight-fit relations such as tight encirclement and tight-fit attachment as distinct relation categories (Choi \& Casasola, 2005). Third, not all semantic categories of spatial relations are seen during infancy, suggesting that not all spatial categories may be formed by simple mapping.

To summarize, children appear to spontaneously categorize at least some relations prior to language acquisition. Furthermore, these preverbal or nonlinguistic categorical distinctions appear to be often of "the right kind" - that is, category distinctions that are important in the semantic systems of many languages.

\section{Cross-linguistic Semantic Variation in Spatial Language}

With the pre-linguistic semantic primitives, the child must learn the language-specific ways to package the spatial relations into words. There is great variation in the way space is semantically partitioned across languages.

In English, while no systematic distinction is made between loose and tight support, the distinction between containment and noncontainment is critical. For example, when seeing a button resting against the palm of a slowly closing hand, English speakers must decide categorically if the object is on or in (Brown, 1973). Especially, instances of on in English are not as homogeneous as instances of containment. For example, putting a ring on a pole (encirclement), putting a Lego piece on another (interlocking attachment), and putting a bottle cap on bottle (interlocking covering) are perceptually highly diverse, compared to the instances of containment relation. Also, English on encodes support relations having various orientations such as a cup on a table (horizontal), a picture on the wall (vertical), leaves on a twig (contact point), and a Band-Aid on a man's body (regardless of the orientation).

However, these relations are treated distinctly in other languages. For example, in Spanish a single preposition, en, is used for the entire range of spatial relations - not distinguishing between support and containment, unless they want to be very explicit (e.g., an apple en a bowl, a cup en a table). Similarly, Japanese has a general locative postposition, $n i$, that is attached to the location noun. This general locative marker can then be further specified by the addition of words like side, top, or front.

In German, those spatial configurations are encoded into three different categories, auf, an, and $u m$, depending on whether a relationship of contact between two objects involves a relatively horizontal surface (table: auf), a vertical or otherwise non-horizontal surface or contact point (wall, twig, leg: an), or encirclement (napkin ring on a napkin: um). Dutch is similar to German in differentiating 
between table and wall, but dissimilar to German in classifying Band-Aid on leg and cup on the table as the same group. Dutch has less to do with orientation than with method of attachment.

There are even more cross-linguistic differences. Finnish maps the suffix -ssa (in) to containment and attachment (picture on the wall, handle on a door), in contrast to the suffix, -lla (on) mapped to support. Korean distinguishes among support, containment, and attachment, using different verbs, nohta (support), nehta (containment), and geolda or puchita (attachment). Korean expresses spatial meanings primarily by means of a variety of different verbs, depending on the figure and referent objects' geometric and functional characteristics. Korean also systematically distinguishes spatial relations based on whether they are tight- or loose-fit relations by mapping a verb (kkita) to tight-fit situations, cutting across the English usages of in and on (kkita) (Choi \& Bowerman, 1991). Conversely, Chalcatongo Mixtec, an Otomanguean language of Mexico, has no prepositions or other locative markers devoting to expressing spatial relationships, similar to Munduruku. Instead, it classifies spatial configurations via an extended and systematic body-part metaphor (Brugman, 1983), classifying "the man is on the roof of the house," "the cat is on the mat," "the tree is on the mountain," and "the boy is on the tree branch" into four different categories. In Mixtec, suggested by the loose translations: the man is located the house's animal-back, the cat is located the mat's face, the tree is located the mountain's head and the boy is located the tree's arm.

Lastly, in their classification of on relationships, English, German and Dutch all ignore the overall shape of the objects and are sensitive to the contact/non-contact between the two objects. If the located object is not in contact with the reference object, but only adjacent to it, a different preposition is needed (e.g., in English, over, above) (Bowerman, 1989).

English makes an obligatory distinction between contact and non-contact when a figure is in position along the positive pole of a vertical axis. If a fly is in contact with a table, one must use on; in contrast, if a fly is any distance from the top side of the table, one must use over or above. This distinction between contact and noncontact is, however, not expressed in the basic spatial terms of Korean. The same spatial term (nominal), wi, can be used for both a fly on a table and the same fly above the table. Korean has phrases that make this distinction that English makes, but one generally does not use such phrases unless the relationship is not clear from context. Thus, the contact/proximal distinction for the vertical axis is collapsed in Korean, but not in English. So although infants start with the same cognitive representations of spatial relations, they must follow different paths as they learn how their own language maps onto these cognitive notions.

\section{Current Knowledge about Children's Spatial Word Meaning Development}

What do we know about the developmental paths? First of all, there is knowledge about the first acquired spatial prepositions in children learning different languages (e.g., Bowerman, 1996; Clark, 1973; Dromi, 1979; Hamilton, Plunkett, \& Schafer, 2000; Johnston \& Slobin, 1979; Landau, 1996; Mandler, 1996; Meints, Plunkett, Harris, \& Dimmock, 2002; Sinha, Thorseng, Hayashi, \& Plunkett, 1994; Tomasello, 1987; Valian, 1986). For example, longitudinal data have revealed that the preposition on can be produced as early as 19 months and under as early as 20 months (Tomasello, 1987). Also, comprehension of on and in in English-learning children has been demonstrated in children as young as 18 months (e.g., Bremner \& Idowu, 1987). They are not fully comprehended until children are around 26-36 months (Clark, 1973; Meints, Plunkett, Harris, \& Dimmock, 2002). Moreover, it has been found that in is understood before on and under (Bowerman, 1996; Brown, 1973; Clark, 1973; Corrigan et al., 1981; Furrow, Murray, \& Furrow, 1986; Halpern, Corrigan, \& Aviezer, 1983; Johnston \& Slobin, 1979; van Geert, 1986). Choi, McDonough, Bowerman, 
and Mandler (1999) demonstrated that by 17 months English- and Korean-speaking children comprehend the terms "in" and "kkita." Children acquiring Hindi and Tzeltal acquire their language-specific distinctions of containment terms as early as 20 to 21 months (Narasimhan \& Brown, 2009). These data, although informative, do not tell us much about how they acquire the meanings of spatial words.

There has been relatively little research about how. Younger infants associate the spatial prepositions only with typical situations, and 24month-olds associate them with atypical situations in which the target was in a less central location, becoming able to associate the prepositions with both typical and atypical types of spatial relations (Meints et al., 2002). Also, De Leon (2001) closely examined the development of 'falling' verb category in children acquiring Tzotzil language, by recording two children's uses of falling verbs from 18 months to 24 months, month-by-month. She found that the expression of vertical motion appears very early in acquisition, both children starting with the most general falling verb $p{ }^{\prime} a j$ 'fall from high' and gradually building up contrasts based on manner of fall, angle of orientation of the Figure, contact of the base of the Figure and the Ground, and body posture resulting from the fall, consistent with the adult forms. Orientation of fall was acquired last. The category of falling was learnt within its boundaries.

One important way to study the developmental paths is to examine the errors that children make during the course of word meaning acquisition. Bowerman (1978, 1989) has pointed out that children's semantic reorganization is often signaled by speech errors. According to her, when children's use of language forms is guided by categories that have been generated independently of linguistic experience, the result is often errors from the adult point of view. Below I present errors that children make about the meanings of spatial terms, scattered in previous literature.

\section{Children's Errors in Spatial Language Acquisition}

First, Bowerman (1976, 1978) found that children make semantic errors with verbs and other relational terms, even quite late in language learning, and often after a period of correct but rather conservative usage. For example, a child has generalized a spatial word behind beyond to its adult borders, saying to her mother "Can I have any reading behind dinner?" meaning "after dinner" (Bowerman, 1978). Interestingly, in languages such as Korean, Chinese, and Japanese, "behind meal" is an typical expression (hou, 後, behind, after). Thus, although the child's utterance is an error (overextension) in English, it is an accurate extension in other languages.

In addition, although Korean- and Englishspeaking children produce their SL spatial terms at an early age (Choi et al., 1999), they still make certain errors. Korean children sometimes overextended kki-ta (tight-fit) to putting magnets on surfaces to which they stick, and ppay-ta (take out) to peeling stickers off surfaces. Similarly, although English-speaking children mastered the obligatory contrast between on/off and in/out situations early, they found the putting together/apart difficult, and often overextended off or open to actions involving the separation of Lego pieces, Pop-beads, and stuck-together Frisbees. Open is also sometimes used for certain off and out situations, and for situations where more specific verbs are needed like unbutton and unfold (Bowerman, 1989). Thus, Korean- and English-speaking children demonstrate similar patterns of errors.

Carey (1978) presents some errors in children's representation of the meanings of spatial adjectives. In one study, young children were shown an array of blocks varying in height and width and asked to indicate the shortest one. Children chose either of the two little ones (i.e., one little in height or one little in width), suggesting that they considered the polarity (-) but failing to use the correct dimension (height). Also, in the same study, when asked to pick the tallest block, most errors were choices of one 
that has the greatest ratio of height to width, again showing a failure to understand the relevance of only one dimension (height) to the word tall. These errors suggest that children include polarity first as spatial adjectives' meanings and underlying dimensionality of each spatial adjective is learned slowly. Other researchers found similar errors (Ervin \& Foster, 1960): children were tuned to the polarity (whether + or -), but confused about the dimensionality. Furthermore, 3- and 4-year-old children's elicitation of opposites of spatial adjectives also revealed that children were almost always correct in terms of the polarity but not in the dimensions. That is, when asked to provide the opposite words, children responded little to wide, little to high, again little to deep, Conversely, when asked for opposites to low, skinny, and short, the child responded big (Carey, 1978). There were also intermediate-stage-like errors such as short to high, tall to low, suggesting that children know that the words apply to the vertical dimension, but their lexical entries still lack the features that distinguish high from tall (skinny to thick, and fat to low are similar).

In the acquisition of "falling" verbs in Tzotzil children, de Leon (1999) found that two children were producing similar errors. In their early use of the verb jach' (slip over, fall backward), both children paid attention to the feature 'lose base' (of Figure and Ground contact), but they did not distinguish directionality of fall, overextending jach' to actions that denote to 'fall forward.' Orientation of fall did not seem to be added to the semantics of the verb until later (de Leon, 1999).

Dromi (1987) conducted a diary study of her daughter from 10 to 17 months of ages. She found that almost all under-extensions were recorded during the initial uses of a new word and that this behavior persisted for a relatively short period of time $(M=2$ weeks, range $=1-10$ weeks). In contrast, overextensions were almost always recorded after a few weeks of correct or restricted use of the same word. This behavior was transient for some words and longer lasting for others. Importantly, she noted that the child was consistent in using such words in her own way despite the parent's regular attempts to provide examples of how to use conventional words in cases of the child's irregular or unclear extension.

Altogether, the currently available error data demonstrate that some errors appear to be universal in children learning different languages; errors persist for some period of time. These errors are important at least for two reasons. First, errors demonstrate that children are not simply parroting back what they have heard in specific contexts, but rather are linking the words to concepts that can be generalized to new situations. Also, errors reveal which distinctions are difficult for children, providing clues to their efforts to work out the needed categories (Bowerman, 1989). If simple pairing experience is completely enough for children's acquisition of spatial word meanings, the range of referents for which children use the words should be closely similar to those for which adult speakers use them, not persistently larger, smaller, or different. However, if the acquisition of spatial word meanings involves a theory creation, children should make errors that reveal the semantic organization. Thus, errors are a good window to see how children's organization of word meanings changes over time, from universal primitives to the conventional meanings.

\section{Proposing Basic Framework for a Theory of Spatial Word Meaning Development}

Based on the review of evidence so far, this section proposes a basic framework for a theory of spatial word meaning development. The proposed framework has essential components as follows.

(1) At the outset of spatial word learning, children possess essential notions about space that are used to divide space and distinguish spatial relations, such as horizontal and vertical axes notions. Preverbal infants' rudimentary categorical distinctions of spatial relations 
probably reflect these notions. More examples may also include contact/separation, distance, direction, containment (inside), and fit. Based on these notions, semantic primitives such as above (over), below (under), left, right, containment, degree of fit, and horizontal support are universally accessed by the child without experiences with linguistic labels. These notions may be called principles and parameters in that they are abstract rules and some specific notions for particular languages can be turned either on or off. These universal principles are displayed through cross-linguistic evidence documenting children's early access of spatial categories, continuous access of those categories, and structure dependence.

(2) Children must learn their Specific Language semantic category system of spatial relations, from real time acoustic data (i.e., spatial words of their specific language) and visual data (i.e., the spatial events or states).

(3) Children's learning of word meaning involves creation of a theory that makes sense to the child. In other words, children build explanations for adults' usage of semantic categories, rather than blindly mimicking what they heard. This theory construction aspect is displayed through the errors that children make.

(4) The universal principles and parameters guide children in their creation of SL semantic system. Without guidelines, children are lost. For example, children may initially map a spatial word (e.g., on) to a known (pre-available) semantic primitive (e.g., vertical axis).
According to the vertical axis, space can be divided into two: the region above the bar and the region under the bar. If the child maps a spatial word to the region above the bar, there are three possibilities. First, the meaning of a spatial word may exactly match that distinction made by the semantic primitive. For example, that distinction based on the vertical axis matches Korean spatial terms "wi" (as opposed to "areh") because Korean does not mark contact versus non-contact obligatorily. A second possibility is that a SL spatial word (semantic category) has a narrower boundary than the child's primitive boundary. For example, for English-learning children, it is required to distinguish between contact-upper region and noncontact-upper region and to use different spatial words on and above. Thus, children make further sophisticated categorical distinctions than they originally had as their primitive distinctions. In this case, the child's understanding of this distinction may be guided by their primitive feature, contact versus non-contact. The child combines multiple primitive features to make the SL semantic distinctions make sense to them. This way, universal semantic primitives may help children to work out the meanings of spatial words. A third possibility is that a semantic category has a wider boundary than children's primitive boundary. For example, when Englishlearning children hear their adults' assigning on to horizontal support, vertical support, and encirclement, children need to collapse and expand some primitive boundaries.

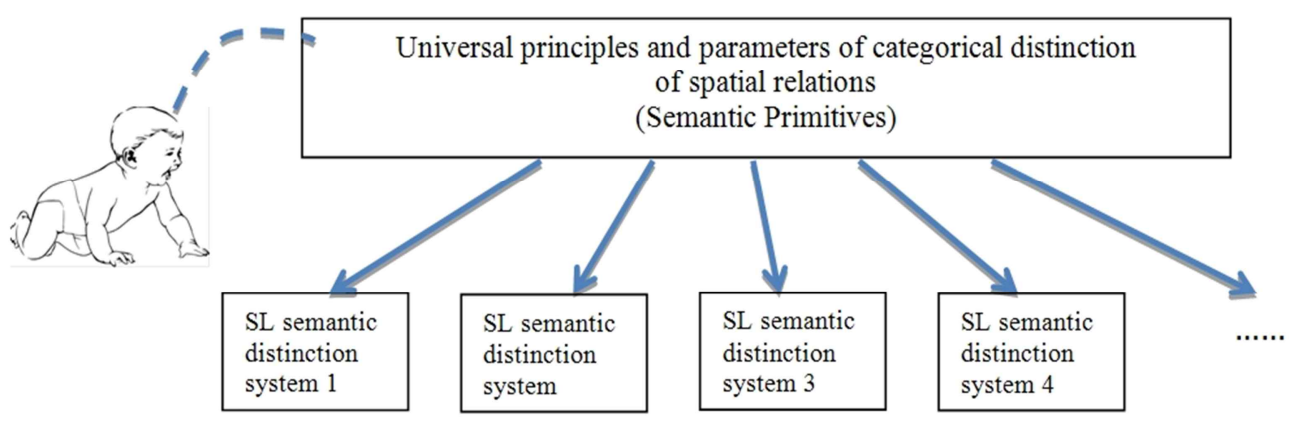

Figure 1. Creation of specific language semantic category system 


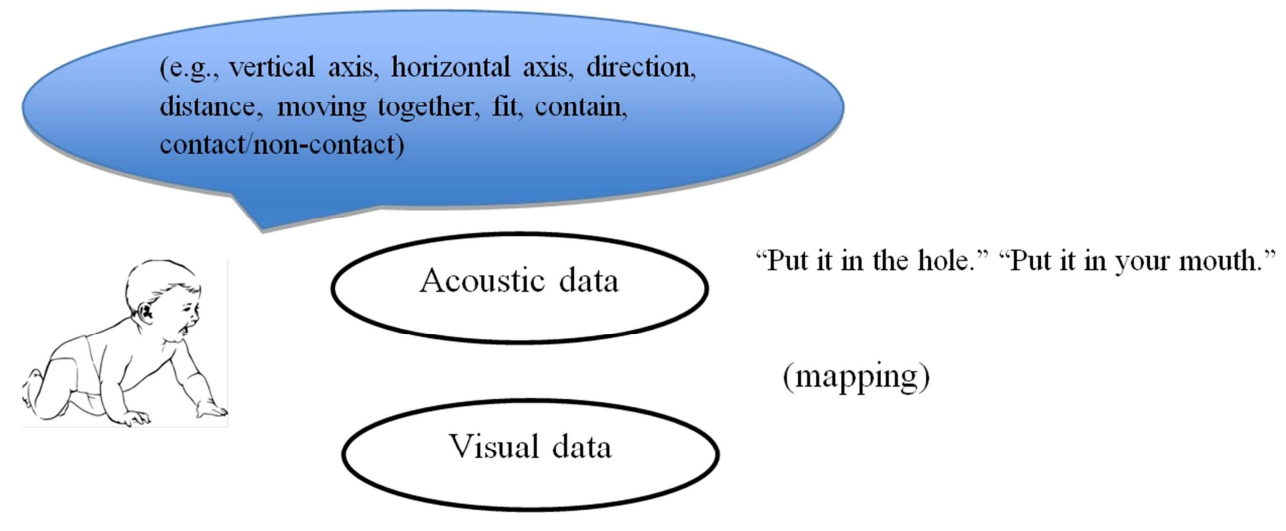

Figure 2. An example of verb learning situation

(5) Overall, our proposal is that the acquisition of spatial word meanings is an adjusting process over time. It may involve pruning, narrowing, and expanding of semantic primitives. It is to create a system by assembling and dissembling the original distinctions. This re-construction process is possible because of both universal principles and experiences over time.

\section{Predictions Based on the Proposed Framework}

Based on the theoretical framework above, the following predictions can be generated.

(1) The theory posits that children have universal principles from the beginning while they have to construct a theory of SL semantic system. Therefore, dissociation between Universal principles and SL semantic categories should be observed within a language. Children will show deficit or difficulty in acquiring language-specific semantic distinctions, not universal principles. In the domain of spatial relations, support relations are semantically more variant across languages (Bowerman \& Choi, 2003). Thus, children in different languages tend to learn more specific-language semantic distinctions of support relations than containment relations. One prediction is then that children will have more difficulty in acquiring support relation terms than acquiring containment relation terms.

There is supporting evidence for this prediction. First, it has been found in many studies that in is understood before on and under (Bowerman, 1996; Brown, 1973; Clark, 1973; Corrigan et al., 1981; Furrow, Murray, \& Furrow, 1986; Halpern et al., 1983; Johnston \& Slobin, 1979; van Geert, 1986). Second, forming an abstract categorical representation of support relations has been shown to be more challenging to infants than forming an abstract categorical representation of containment relations (e.g., Casasola \& Cohen, 2002). For stronger support for this prediction, evidence that Englishlearning children make errors (e.g., underextension) in the course of learning the spatial term on. Also, German distinguishes horizontal versus vertical support relations (auf vs. ann), and Korean distinguishes tight versus loose support relations (kitta vs. nohta). Longitudinal data in generalization (i.e., word extension) tests from children learning these languages will be also very helpful.

(2) The framework proposes that the child creates a theory about the SL semantic distinctions. If it is the case, children will produce errors that are not errors in other languages. That is, errors show universal influences. Also, these errors should not be 
"mistakes" but be consistent on several different tasks that test the same labels. Because errors will reflect their current theory, sometimes they might resist adult distinctions.

Currently there are very little data about children's errors in spatial words. Allen and colleagues (2007) found that Japanese and Turkish children used tight syntactic packaging of manner and path unlike their adult counterparts. The tight syntactic packaging of manner and path is not typical in their languages but are the most typical in English-speaking children and adults. Collecting of children's error data across different languages is needed. Also, developing tasks that elicit children's descriptions of spatial relations (relations that cross-linguistically vary) will be helpful.

(3) The theory posits that universal primitives have strong continuity. That is, universal principles and parameters for differentiation and synthesis are not lost even after children establish their specific language semantic category system. If that is the case, the universal principles will be evident in more complex tasks or nonlinguistic tasks or second-language learning.

Some supporting data are currently available. In some nonlinguistic tasks, adults show sensitivity to distinction of spatial relations that is not obligated to express in their language. For example, Norbury, Waxman, and Song (2008) found that adult English speakers could pick up the tight-fit feature in a similarity judgment test. They also found an asymmetry between tight-fit and loose-fit features: tight-fit feature is better picked up than loose-fit features by both Korean speakers and English speakers. Also, Choi and Hattrup (2012) demonstrated that containment and tight-fit features appear to be perceptually salient to speakers of any language, supporting the idea that the universal distinction principle is not lost, but is evident in nonlinguistic tasks even in adults.

If future research examines the ability to acquire different spatial semantic categories of a second language, it will be one of the ways to test whether semantic primitives not used in the first language remain available and are attended to as needed for the second language.

\section{Conclusion}

In this paper we attempted to explore the possibility of applying Grammatical Mapping theory in syntactic acquisition to children's semantic development, especially spatial word meaning acquisition. However, the proposed framework is by no means completely novel. Slobin (1985) has proposed a similar view: "a form that is at first linked to a universal core meaning that is too narrow may gradually be extended to situations that are increasingly dissimilar to the core, until language-appropriate boundaries have been reached. Conversely, a form associated with a too-broad meaning may gradually have its range of application cut back." The important strength of these views is that it acknowledges both universal principles and children's sensitivity to their particular language's system.

Thus, back to the existing theories of word meaning development, the proposed theoretical framework can be seen to add two elements to the Bowerman's multil-factorial theory. First, children may sometimes simply map language forms to existing concepts. Second, children are capable of organizing language-specific categories by observing data and making inferences about the categorization principles, but that organization is guided and constrained by the universal and essential principles and parameters.

Finally, as the review of evidence shows, little research has examined developmental changes that occur during the journey of word meaning acquisition. To better understand whether there are semantic primitives, and if so, how children acquire specific language semantic category system based on the semantic primitives, we need cross-linguistic investigations closely documenting changes in how the child uses spatial words over time. This work will also help us to answer how general or specific the primitives are. 


\section{References}

Aguiar, A., \& Baillargeon, R. (1998). Eight-anda-half-month-old infants' reasoning about containment events. Child Development, 69, 636-653.

Allen, S., Özyürek, A., Kita, S., Brown, A., Furman, R., Ishizuka, T., \& Fujii, M. (2007). Language-specific and universal influences in children's syntactic packaging of manner and path: A comparison of English, Japanese, and Turkish. Cognition, 102, 16-48.

Antell, S. E. G., \& Caron, A. J. (1985). Neonatal perception of spatial relationships. Infant Behavior and Development, 8, 15-23.

Baillargeon, R. (1994). How do infants learn about the physical world? Current Directions in Psychological Science, 3,133-140.

Baillargeon, R. (2004). Infants' physical knowledge. Current Directions in Psychological Science, 13, 88-94.

Baillargeon, R., Needham, A., \& DeVos, J. (1992). The development of young infants' intuitions about support. Early Development and Parenting, 1, 69-78.

Baldwin, D. A., \& Tomasello, M. (1998). Word learning: A widow on early pragmatic understanding. In E. V. Clark (Ed.), Proceedings of the Stanford child language research forum. Stanford, CA: Center for the Study of Language and Information.

Barrett, M. D. (1995). Early lexical development. In P. Fletcher \& B. MacWhinney (Eds.), The handbook of child language (pp.362-392). Oxford: Blackwell.

Bowerman, M. (1976). Semantic factors in the acquisition of rules for word use and sentence construction. In D. M. Morehead \& A. E. Morehead (Eds.), Normal and deficient child language (pp. 99-179). Baltimore, MD: University Park Press.

Bowerman, M. (1978). Systematizing semantic knowledge: Change over time in the child's organization of word meaning. Child Development, 49, 977-987.

Bowerman, M. (1989). Learning a semantic system: What role do cognitive predispositions play? In M. L. Rice \& R. L. Shiefelbusch
(Eds.), The teachability of language (pp.133169). Baltimore: Paul H. Brookes.

Bowerman, M. (1996). Learning how to structure space for language: A crosslinguistic perspective. In P. Bloom, M. Peterson, L. Nadel, \& M. Garrett (Eds.), Language and space (pp.385-486). Cambridge, MA: MIT Press.

Bowerman, M., \& Choi, S. (2001). Shaping meanings for language: Universal and language-specific in the acquisition of spatial semantic categories. In M. Bowerman \& S. Levinson (Eds.), Language acquisition and conceptual development (pp.475-511). Cambridge: Cambridge University Press.

Bowerman, M., \& Choi, S. (2003). Space under construction: Language-specific spatial categorization in first language acquisition. In D. Gentner \& S. Goldin-Meadow (Eds.), Language in mind: Advances in the study of language and cognition (pp.387-428). Cambridge, MA: MIT Press.

Bremner, G. J., \& Idowu, T. C. (1987). Constructing favorable conditions for measuring the young child's understanding of the terms in, on and under. International Journal of Behavioral Development, 10, 8998.

Brown, R. (1958). Words and things: An introduction to language. Glencoe, IL: The Free Press.

Brown, R. (1973). A first language. Cambridge: Cambridge University Press, 145-176.

Brugman, C. (1983). The use of body-part terms as locatives in Chalcatongo Mixtec. Studies in Mesoamerican linguistics. In A. Schlichter (Ed.), Survey of California and other Indian languages, 4 (pp.235-290). Berkeley, CA.

Carey, S. (1978). The child as word learner. In M. Halle, J. Bresnan, \& A. Miller (Eds.), Linguistic theory and psychological reality (pp.264-293). Cambridge, MA: MIT Press.

Carey, S. (1993). Ontology and meaning-Two contrasting views. In E. Dromi (Ed.), Language and cognition: A developmental perspective (pp.88-103). Norwood, NJ: Ablex.

Casasola, M., \& Cohen, L. (2002). Infant categorization of containment, support, and 
tight-fit spatial relationships. Developmental Science, 5, 247-264.

Casasola, M., Cohen, L., \& Chiarello, E. (2003). Six-month-old infants' categorization of containment spatial relations. Child Development, 74, 679-693.

Choi, S., \& Bowerman, M. (1991). Learning to express motion events in English and Korean: The influence of language-specific lexicalization patterns. Cognition, 41, 83-121.

Choi, S., \& Casasola, M. (2005). Preverbal categorization of support relations. Paper presented at the Society for Research in Child Development, Atlanta, GA.

Choi, S., \& Hattrup, K. (2012). Relative contribution of perception/cognition and language on spatial categorization. Cognitive Science, 36, 102-129.

Choi, S., McDonough, L., Bowerman, M., \& Mandler, J. M. (1999). Early sensitivity to language-specific spatial categories English and Korean. Cognitive Development, 14, 241268.

Clark, E. V. (1973). Non-linguistic strategies and the acquisition of word meanings. Cognition, 2, 161-182.

Clark, E. V. (1983a). Convention and contrast in acquiring the lexicon. In B. Seiler \& W. Wannenmacher (Eds.), Concept development and the development of word learning (pp.6789). Berlin, Germany: Springer-Verlag.

Clark, E. V. (1983b). Meanings and concepts. In J. H. Flavell \& E. M. Markman (Eds.), Handbook of child psychology, Vol. 3, Cognitive development (pp.787-840). New York: John Wiley \& Sons.

Clark, E. V. (1988). On the logic of contrast. Journal of Child Language, 15, 317-337.

Clark, E. V. (1993). The lexicon in acquisition. Cambridge, UK: Cambridge University Press.

Clark, H., \& Clark, E. (1977). Psychology and language. New York: Harcourt, Brace, Jovanovich.

Corrigan, R., Halpern, E., Aviezer, O., \& Goldblatt, A. (1981). The development of three spatial concepts: In, on, under. International Journal of Behavioral Development, 4, 403-419.
Dehaene, S., Izard, V., Pica, P., \& Spelke, E. (2006). Core knowledge of geometry in an Amazonian indigene group. Science, 311, 381-384.

de León, L. (1999). Verb roots and caregiver speech in early Tzotzil acquisition. In B. A. Fox, D. Jurafsky, \& L. A. Michaelis (Eds.), Cognition and function in language (pp.99119). Stanford, CA: Stanford University Center for Language and Information.

de León, L. (2001). Finding the richest path: Language and cognition in the acquisition of verticality in Tzotzil (Mayan). In $M$. Bowerman \& S. C. Levinson (Eds.), Language acquisition and conceptual development. Cambridge: Cambridge University Press.

Dromi, E. (1979). More on the acquisition of locative prepositions: An analysis of Hebrew data. Journal of Child Language, 6, 547-562.

Dromi, E. (1987). Early lexical development. Cambridge: Cambridge University Press.

Ervin, S. M., \& Foster, G. (1960). The development of meaning in children's descriptive terms. Journal of Abnormal and Social Psychology, 60, 271-275.

Furrow, D., Murray, P., \& Furrow, M. (1986). Spatial term use and its relation to language function at two developmental stages. First Language, 6, 41-51.

Gava, L., Valenza, E., \& Turati, C. (2009). Newborns' perception of left-right spatial relations. Child Development, 80, 1797-1810.

Gentner, D. (1982). Why nouns are learned before verbs: Linguistic relativity versus natural partitioning. In S. Kuczaj II (Ed.), Language, thought and culture. Hillsdale, NJ: Lawrence Erlbaum.

Golinkoff, R. M., \& Hirsh-Pasek, K. (2006). Baby wordsmith: From associationist to social sophisticate. Current Directions in Psychological Science, 15, 30-33.

Halpern, E., Corrigan, R., \& Aviezer, O. (1983). In, on, and under: Examining the relationship between cognitive and language skills. International Journal of Behavioral Development, 6, 153-166.

Hamilton, A., Plunkett, K., \& Schafer, G. (2000). 
Infant vocabulary development assessed with a British Communicative Development Inventory: Lower scores in the UK than in the USA. Journal of Child Language, 27, 689705.

Hespos, S., \& Baillargeon, R. (2001). Reasoning about containment events in very young infants. Cognition, 78, 207-245.

Hespos, S., \& Spelke, E. (2004). Conceptual precursors to language. Nature, 430, 453-456.

Hespos, S., \& Piccin, T. (2009). To generalize or not to generalize: Spatial categories are influenced by physical attributes and language. Developmental Science, 12, 88-95.

Hirsh-Pasek, K., Golinkoff, R., \& Hollich, G. (2000). An emergentist coalition model for word learning: Mapping words to objects is a product of the interaction of multiple cues. In R. M. Golinkoff, K. Hirsh-Pasek, L. Bloom, L. Smith, A. Woodward, N. Akhtar, M. Tomasello, \& G. Hollich (Eds.), Becoming a word learner: A debate on lexical acquisition. New York: Oxford University Press.

Hollich, G. J., Hirsh-Pasek, K., \& Golinkoff, R. M. (2000). Breaking the language barrier: An emergentist coalition model for the origins of word learning. Monographs of the Society for Research in Child Development, 65, (3, Serial No. 262).

Johnston, J., \& Slobin, D. I. (1979). The development of locative expressions in English, Italina, Serbo-Croatian and Turkish. Journal of Child Language, 6, 529-545.

Landau, B. (1996). Multiple geometric representations of objects in languages and language learners. In P. Bloom, M. A. Peterson, L. Nadel, \& M. F. Garrett (Eds.), Language and space (pp.317-363). Cambridge, MA: MIT Press.

Lust, B. (2012). Tracking universals requires grammatical mapping paradigm. Linguists of tomorrow: Selected papers from the First Cyprus Postgraduate Conference in theoretical and applied linguistics. Cambridge scholars publishing, UK. pp.105-130.

Mandler, J. (1992). How to build a baby: II Conceptual primitives. Psychological Review, 99, 587-604.
Mandler, J. M. (1996). Preverbal representation and language. In P. Bloom, M. A. Peterson, L. Nadel, \& M. F. Garrett (Eds.), Language and space (pp.365-384). Cambridge, MA: MIT Press.

Markman, E. M. (1989). Categorization and naming in children: Problems of induction. Cambridge, MA: MIT Press.

Markman, E. M. (1991). The whole object, taxonomic, and mutual exclusivity assumptions as initial constraints on word meanings. In J. P. Byrnes \& S. A. Gelman (Eds.), Perspectives on language and thought: Interrelations in development (pp.72-106). Cambridge, UK: Cambridge University Press.

McDonough, L., Choi, S., \& Mandler, J. M (2003). Understanding spatial relations: Flexible infants, lexical adults. Cognitive Psychology, 46, 229-259.

Meints, K., Plunkett, K., Harris, P. L., \& Dimmock, D. (2002). What is 'on' and 'under' for 15-, 18- and 24-month-olds? Typicality effects in early comprehension of spatial prepositions. British Journal of Developmental Psychology, 20, 113-130.

Narasimhan, B., \& Bown, P. (2009). Getting the INSIDE story: Learning to talk about containment in Tzeltal and Hindi. In V. C. Mueller Gathercole (Ed.), Routes to language: Studies in honor of Melissa Bowerman (pp.97-132). New York: Psychology Press.

Needham, A., \& Baillargeon, R. (1993). Intuitions about support in 4.5-month-old infants. Cognition, 47, 121-148.

Nelson, K. (1985). Making sense: The acquisition of shared meaning. New York: Academic Press.

Norbury, H., Waxman, S., \& Song, H. (2008). Tight and loose are not created equal: An asymmetry underlying the representation of fit in English and Korean speakers. Cognition, 109, 316-325.

Park, Y., \& Casasola, M. (under review). Plain or decorated? Object visual features matter in infant spatial categorization.

Plumert, J. M., \& Hawkins, A. M. (2001). Biases in young children's communication about 
spatial relations: Containment versus proximity. Child Development, 72, 22-36.

Pruden, S. M., Hirsh-Pasek, K., Golinkoff, R. M., \& Hennon, E. A. (2006). The birth of words: Ten-month-olds learn words through perceptual salience. Child Development, 77, 266-280.

Quinn, P. (1994). The categorization of above and below spatial relations by young infants. Child Development, 65, 58-69.

Quinn, P., Cummins, M., Kase, J., Martin, E., \& Weissman, S. (1996). Development of categorical representations for above and below spatial relations in 3- to 7-month-old infants. Developmental Psychology, 32, 942950.

Saji, N., Imai, M., Saalbach, H., Zhang, Y., Shu, H., \& Okada, H. (2011). Word learning does not end at fast-mapping: Evolution of verb meanings through reorganization of an entire semantic domain. Cognition, 118, 45-61.

Sinha, C. G., Thorseng, L. A., Hayashi, M., \& Plunkett, K. (1994). Comparative spatial semantics and language acquisition: Evidence from Danish, English, and Japanese. Journal of Semantics, 11, 253-287.

Slobin, D. I. (1985). Crosslinguistic evidence for the language-making capacity. In D. I. Slobin (Ed.), The crosslinguistic study of language acquisition (vol.2, pp.1157, 1256). Hillsdale, NJ: Erlbaum.
Smith, L. B. (1999). Children's noun learning: How general learning processes make specialized learning mechanisms. In B. MacWhinney (Ed.), The emergence of language (pp.227-305). Mahwah, NJ: Erlbaum.

Tomasello, M. (1987). Learning to use prepositions: A case study. Journal of Child Language, 14, 79-98.

Tomasello, M. (2000). The social-pragmatic theory of word learning. Pragmatics, 10, 401413.

Tomasello, M., \& Barton, M. (1994). Learning words in nonostensitve context. Developmental Psychology, 30, 639-650.

Tomasello, M., \& Farrar, J. (1986). Joint attention and early language. Child Development, 57, 1454-1463.

Valian, V. (1986). Syntactic categories in the speech of young children. Developmental Psychology, 22, 562-579.

van Geert, P. (1986). In, on, under: An essay on the modularity of infant spatial competence. First Language, 6, 7-28.

Wang, S., Baillargeon, R., \& Paterson, S. (2005). Detecting continuity violations in infancy: A new account and new evidence from covering and tube events. Cognition, 95, 129-173.

Received February 10, 2015 Revision Received February 24, 2015 Accepted February 25, 2015 


\section{Appendix}

\section{Constraints Theory}

One influential theory on word meaning acquisition is constraints theory that children utilize a priori built-in constraints in acquiring the meanings of words. Markman $(1989,1991)$ articulated three constraints-whole object, taxonomic, and mutual exclusivity: When children are exposed to a new word in the presence of a novel object, they assume that: the new word labels the whole object rather than its parts, substance, or other properties; that the new word labels a class of objects rather than objects that are thematically related; that the new word cannot be a second name for the same object if children already have a name for the object (see also Carey, 1993). E. Clark (1983a, 1983b, 1988) offered two additional constraints: contrast and conventionality: Any word in the lexicon contrasts in meaning with any other word; and every word in the language has a conventional meaning that is shared by all speakers in the same language community (Clark, 1993). The constraints theories nevertheless explain the first step of word learning, which is fast mapping but provide little account for the acquisition of word meanings that take place over the extended time, complexive uses of words (e.g., Bowerman, 1978), and contextual use of first words by young children. Also, it is primarily focused on object word leaning, and thus it is unclear whether the constraints can apply to children's acquisition of relational terms such as spatial prepositions.

\section{Social Pragmatic Theory}

Children learn to identify the different referents based on adults' attentional and intentional states. Tomasello and colleagues demonstrate toddlers' sensitivity to subtle social cues that adults provide to facilitate the mapping of new words with unnamed novel objects or novel actions (e.g., Baldwin \& Tomasello, 1998; Hollich et al., 2000; Tomasello \& Barton, 1994;
Tomasello \& Farrar, 1986). This theory also attempts to explain children's fast mapping despite of the problem of correct mapping with "an infinitude of possibilities (Carey, 1993).

\section{Emergentist Coalition Model}

Finally, Hollich, Golinkoff, and Hirsh-Pasek (2000) proposed an emergentist coalition model. The model suggests that children have access to a number of co-occurring cues for word learning (including perceptual, social, and linguistic), that they can utilize at different times along the extended process of word meaning acquisition (Golinkoff \& Hirsh-Pasek, 2006;). Particularly, at an early age infants pair words with perceptually salient objects (Smith, 1999; Pruden, Hirsh-Pasek, Golinkoff, \& Hennon, 2006). Later on, at around the age of 12 months infants begin to appreciate the importance of the social cues and become more sensitive to the social cues that adults provide in order to signal the intended meaning of a new word to the child. Only after gaining a wealth of experience in learning new words (when they are about 18 to 24 months of age) do children begin to utilize social pragmatic cues for rapid and efficient word learning (Pruden et al., 2006). 